\title{
Processing Biochar from Solid Waste of Arenga Pinnata Flour Industry
}

\author{
Susanti Rina Nugraheni ${ }^{1)}$, Agus Prasetya ${ }^{2)}$, and Sihana ${ }^{3)}$ \\ ${ }^{1}$ Program Studi Teknik Kimia, FTI, UPN"Veteran" Yogyakarta \\ Jln. SWK 104 (Lingkar Utara), Condongcatur, Yogyakarta \\ ${ }^{2}$ Chemical Engineering Department, UGM \\ Jalan Grafika 2, Kampus UGM, Yogyakarta \\ ${ }^{3}$ Physics Engineering Department, UGM \\ Jalan Grafika 2, Kampus UGM, Yogyakarta \\ "E-mail: susantirina22@gmail.com
}

\begin{abstract}
Arenga pinnata solid waste can be used as biochar-making material because it contains biomass agriculture and forestry residue. This research purposed to know the effect of pyrolysis in yield and characteristic of biochar as soil amendment. The research done by making model and practice the model. The variables of this research were : temperature, biochar yield, C-organic content, water content, $\mathrm{pH}, \mathrm{N}, \mathrm{P}$, and $\mathrm{K}$. The raw materials weight that used in each pyrolysis process is 200 grams. The result from this research are the highest biochar yield from arenga pinnata with 200 grams of raw materials weight was at $300-500{ }^{\circ} \mathrm{C}$ of temperature and $210-240$ minutes of processing time with $>30 \%$ of yield. The test with temperature variations show : 1) at $300-400{ }^{\circ} \mathrm{C}$ of temperature acquired $4,45 \%$ of water content, 5,6 of $\mathrm{pH}$, $14,63 \%$ of C-organic content, $0,71 \%$ of Nitrogen, $0,10 \%$ of Phosphor, and $0,63 \%$ of Kalium, 2) at $400-500{ }^{\circ} \mathrm{C}$ of temperature acquired $5,62 \%$ of water content, 5,26 of $\mathrm{pH}, 13,49 \%$ of C-organic content, $0,73 \%$ of Nitrogen, $0,13 \%$ of Phosphor, and $0,49 \%$ of Kalium, 3) at $500-600{ }^{\circ} \mathrm{C}$ of temperatur acquired $3,22 \%$ of water content, 6,1 of $\mathrm{pH}, 15,66 \%$ of C-organic content, $0,92 \%$ of Nitrogen, $0,09 \%$ of Phospor, and $0,58 \%$ of Kalium. The results from this research were able to fulfill the regulation as soil amendment determined by International Biochar Initiative (2010).
\end{abstract}

Keywords: Arenga pinata waste, biochar, pyrolysis, temperature variable, and soil amendment.

\section{I.Pendahuluan.}

Desa Daleman yang terletak di wilayah bagian utara Kabupaten Klaten tepatnya di Kecamatan Tulung, jumlah penduduk 4994 jiwa, dengan jumlah KK 1205. Di wilayah Desa Daleman terdapat sentra industri tepung aren yang merupakan bagian dari industri kecil dan rumah tangga di Kabupaten Klaten. Tepung aren merupakan bahan baku untuk membuat soun, cendol, bakmi, bakso, hunkwe, dll.

Proses pengolahan tepung aren diawali dengan pembelahan batang aren menjadi empat bagian tiap potongnya. Kemudian bagian dalam batang aren di parut dengan parutan mesin hingga tersisa kulit batang aren. Hasil dari parutan kemudian direndam dalam bak air dan disaring ampas kasarnya. Hasil pemerasan dibiarkan sehingga patinya akan mengendap pada dasar bak. Dari proses pembuatan tepung aren dihasilkan limbah berupa cair dan padat. Limbah cair berasal dari proses penyaringan dan pengendapan tepung aren, sementara limbah padat yang berupa kulit batang aren berasal dari sisa pemarutan batang serat dan ampas serat aren yang berasal dari proses penyaringan. Menurut Kepala Desa Baghtiar Joko Widagdo, jumlah limbah aren biasanya mencapai 50 ton per hari.

Teknologi yang akan digunakan untuk mengolah limbah padat aren adalah mengubahnya menjadi biochar (arang hayati) dengan proses pirolisis. Biochar adalah material karbon padat yang dihasilkan dari degradasi secara thermal (biomassa/bahan organik) pada kondisi sedikit atau tanpa oksigen (Lehmann et. al., 2009).
Karena berasal dari makhluk hidup kita sebut arang hayati. Di dalam tanah, biochar dapat meningkatkan kesuburan tanah, mengikat karbon dalam tanah, dan menyediakan habitat yang baik bagi mikroba tanah, tapi tidak dikonsumsi seperti bahan organik lainnya. Dalam jangka panjang biochar tidak menganggu keseimbangan karbon-nitrogen, bahkan mampu menahan dan menjadikan air dan nutrisi lebih tersedia bagi tanaman (Gani, 2010)

\section{II.Metodologi.}

Bahan baku berupa ampas aren diambil dari limbah pembuatan tepung aren di Desa Daleman, Tulung, Klaten. Bahan baku ampas aren terdiri dari serbuk halus dan serat kasar dikeringkan dengan cara dijemur dibawah sinar matahari selama beberapa hari agar benarbenar kering dan kadar airnya berkurang. Kemudian dilakukan analisis awal di laboratorium untuk mengeyahui kadar air, lignin, dan selulosanya. Setelah hasil analisis diketahui, bahan ditimbang sesuai dengan variasi kebutuhan yaitu maksimal 200 gram bahan baku untuk satu kali proses pirolisis.

Alat yang digunakan dalam penelitian ini terdiri dari satu set alat pirolisis dengan menggunakan kompor gas, dengan kapasitas 200 gram ampas aren sebagai bahan baku. Sedangkan alat pendukung yang digunakan antara lain : timbangan, lembaran asbes, penjepit, kamera digital, stopwatch (penghitung waktu), multimeter digital, kertas dan ballpoint. 
Gambar 1.

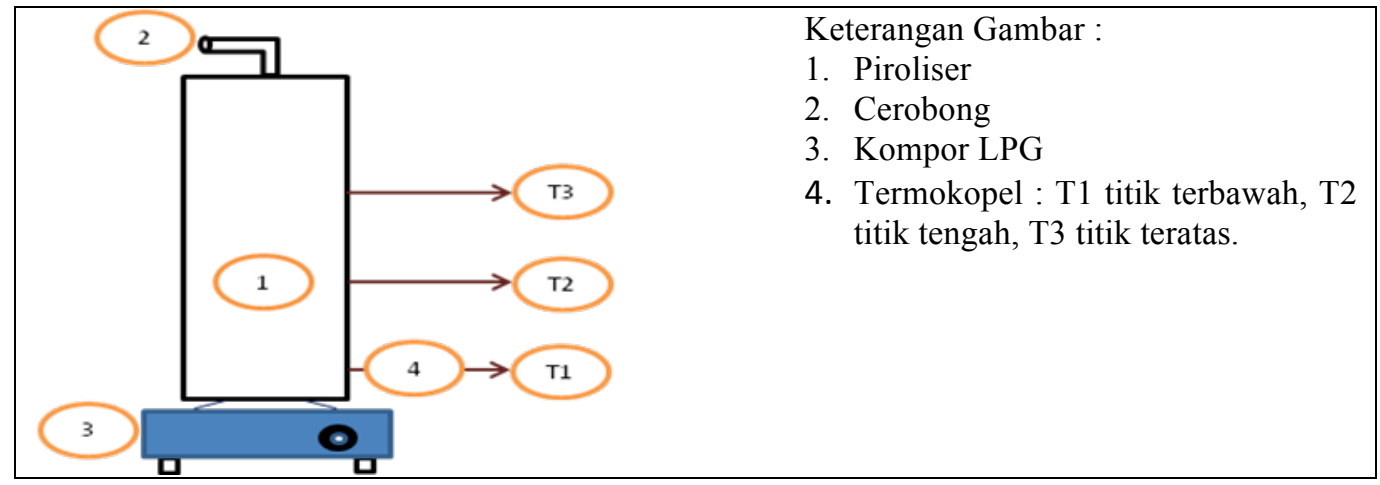

Gambar 1. Rangkaian alat pirolisis

Pertama kali dilakukan adalah menyiapkan kompor LPG pada tempatnya. Kemudian, bahan baku yang sudah ditimbang dimasukkan ke tabung pirolisis dan tutup tabung dipasang rapat dengan memberi tambahan bantalan asbes agar tidak ada celah udara. Tabung pirolisis diletakkan diatas kompor dengan posisi tepat di tengah-tengah kompor.Setelah semua peralatan siap, kompor LPG dinyalakan. Suhu diusahakan stabil dengan cara melihat voltase yang ditunjukkan pada multimeter digital dengan memutar volume kompor LPG. Pada proses pirolisis, volatile matter akan menguap, mengalir keluar melalui lubang pipa. Sehingga didalam tabung pirolisis hanya tersisa arang (char). Selanjutnya, peralatan dimatikan dan didiamkan sampai mendekati suhu kamar. Setelah itu tutup tabung dibuka secara perlahan dan arang dikeluarakan dan dipisahkan antara arang dan yang bukan arang, kemudian masing-masing ditimbang.

Data yang diperoleh akan dicatat dalam tabel, kemudian dianalisis untuk menentukan pengaruh temperatur terhadap rendemen dan karakteristik biochar. Rendemen arang dapat ditentukan dengan membandingkan berat arang yang dihasilkan dengan berat bahan baku. Sampel ampas aren yang telah dikeringkan (dijemur) ditimbang sebanyak 200 gram. Kemudian arang hasil pirolisis pada masing-masing temperatur ditimbang. Rendemen biochar (R) hasil pirolisis dapat dihitung dengan rumus :
$\mathrm{R}=\frac{\text { massa biochar }}{\text { massa bahan baku }} \times 100 \%$

Kemudian, uji laboratorium produk dilakukan dengan menghitung kadar C-Organik, kadar air, $\mathrm{pH}, \mathrm{N}, \mathrm{P}$, dan $\mathrm{K}$.

\section{III.Hasil dan Pembahasan.}

Pada penelitian ini dilakukan untuk variasi temperatur seperti pada range suhu $300-400{ }^{\circ} \mathrm{C}, 400-500{ }^{\circ} \mathrm{C}$, dan $500-600{ }^{\circ} \mathrm{C}$. Setelah suhu tercapai seperti yang ditentukan, pembakaran dibatasi dengan cara mengecilkan volume pada kompor LPG, sehingga suhu tetap terjaga dalam range yang ditentukan. Seterusnya dilakukan selama waktu tertentu pada range suhu yang diinginkan agar rendemen yang dihasilkan 100\% atau mendekati $100 \%$ arang.

3.1. Proses Pirolisis Pada Range Suhu $300-400{ }^{\circ} \mathrm{C}$. Pada Gambar 2. proses pirolisis dengan berat bahan baku ampas aren 200 gram. Terlihat proses pirolisis untuk suhu T1 (titik bawah), suhu tertinggi tercapai mulai pada menit 180 , yaitu $396^{\circ} \mathrm{C}$. Untuk suhu T2 (titik tengah), suhu tertinggi tercapai mulai pada menit 210 , yaitu $305{ }^{\circ} \mathrm{C}$. Dan untuk suhu T3 (titik atas), suhu tertinggi tercapai mulai pada menit 210 , yaitu $287{ }^{\circ} \mathrm{C}$. Selanjutnya suhu dijaga pada range $300-400{ }^{\circ} \mathrm{C}$ sampai akhir proses.

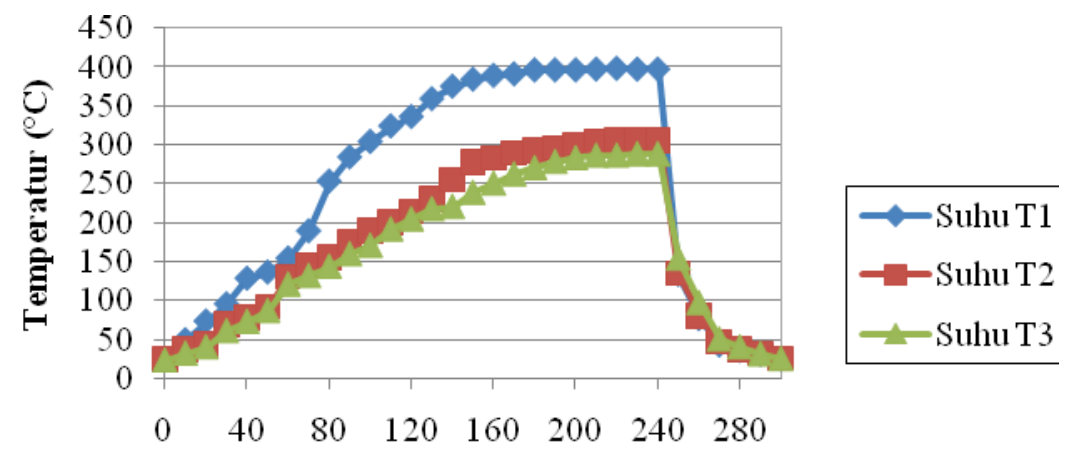

Waktu (menit) 
Gambar 2. Kenaikan suhu pada proses pirolisis $\left(300-400{ }^{\circ} \mathrm{C}\right)$

3.2. Proses Pirolisis Pada Range Suhu $400-500{ }^{\circ} \mathrm{C}$. Pada Gambar 3. proses pirolisis dengan berat bahan baku ampas aren 200 gram. Terlihat proses pirolisis untuk suhu T1 (titik bawah), suhu tertinggi tercapai mulai pada menit 170 , yaitu $488{ }^{\circ} \mathrm{C}$. Untuk suhu T2 (titik tengah), suhu tertinggi tercapai mulai pada menit 190, yaitu $395^{\circ} \mathrm{C}$. Dan untuk suhu T3 (titik atas), suhu tertinggi tercapai mulai pada menit 190 , yaitu $362{ }^{\circ} \mathrm{C}$. Selanjutnya suhu dijaga pada range $400-500{ }^{\circ} \mathrm{C}$ sampai akhir proses.

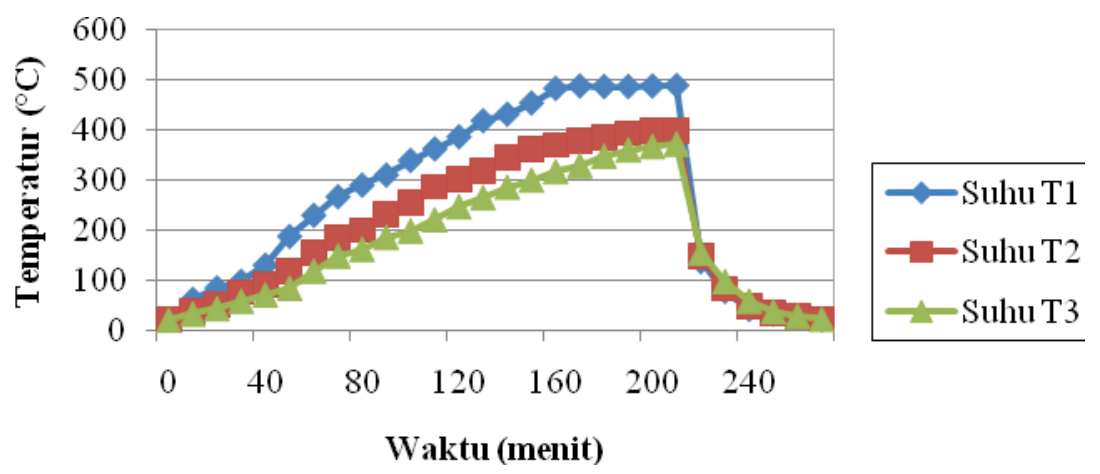

Gambar 3. Kenaikan suhu pada proses pirolisis $\left(400-500{ }^{\circ} \mathrm{C}\right)$

\subsection{Proses Pirolisis Pada Range Suhu $500-600{ }^{\circ} \mathrm{C}$}

Pada Gambar 4. proses pirolisis dengan berat bahan baku ampas aren 200 gram. Terlihat proses pirolisis untuk suhu T1 (titik bawah), suhu tertinggi tercapai mulai pada menit 130 , yaitu $558{ }^{\circ} \mathrm{C}$. Untuk suhu T2 (titik tengah), suhu tertinggi tercapai mulai pada menit 160, yaitu $468^{\circ} \mathrm{C}$. Dan untuk suhu T3 (titik atas), suhu tertinggi tercapai mulai pada menit 160 , yaitu $393{ }^{\circ} \mathrm{C}$. Selanjutnya suhu dijaga pada range $500-600{ }^{\circ} \mathrm{C}$ sampai akhir proses

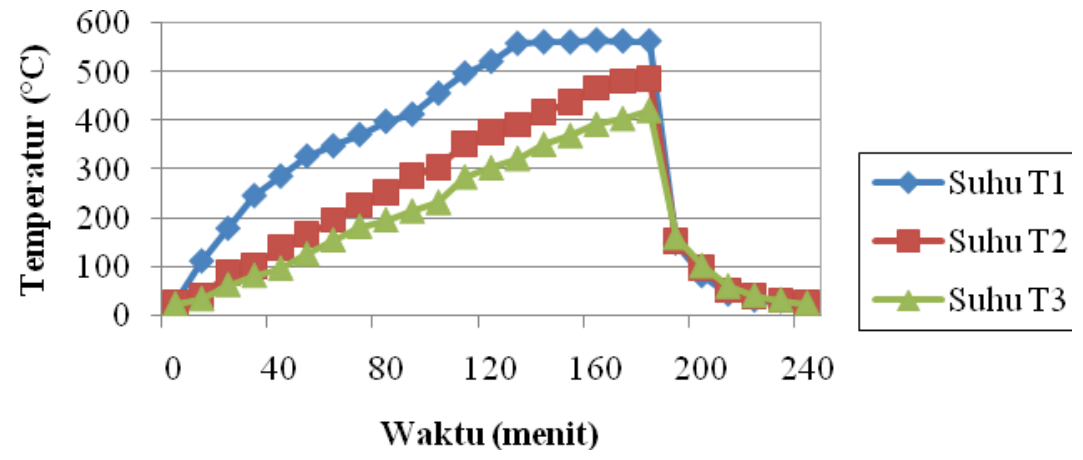

Gambar 4. Kenaikan suhu pada proses pirolisis $\left(500-600{ }^{\circ} \mathrm{C}\right)$

\subsection{Rendemen Biochar.}

Berdasarkan hasil dari penelitian yang telah dilakukan dengan temperatur yang berbeda dan berat bahan baku ampas aren yang sama untuk setiap kali proses pirolisis, yaitu 200 gram, terdapat pengaruh yang tidak terlalu signifikan pada suhu $300-500^{\circ} \mathrm{C}$ terhadap rendemen biochar.

Tabel 1. Rendemen biochar (\%) terhadap umpan

\begin{tabular}{ccccc}
\hline No. & $\begin{array}{c}\text { Ampas Aren } \\
(\text { gram })\end{array}$ & $\begin{array}{c}\text { Temperatur } \\
\left({ }^{\circ} \mathbf{C}\right)\end{array}$ & $\begin{array}{c}\text { Bio-char }(\mathbf{R}) \\
(\mathbf{\%})\end{array}$ & $\begin{array}{c}\text { Ampas Aren Yang } \\
\text { Tidak Terpirolisis } \\
(\%)\end{array}$ \\
\hline 1. & 200 & $300-400$ & 37,5 & 22,5 \\
2. & 200 & $400-500$ & 32,5 & 2,5 \\
3. & 200 & $500-600$ & 22,5 & 0 \\
\hline
\end{tabular}




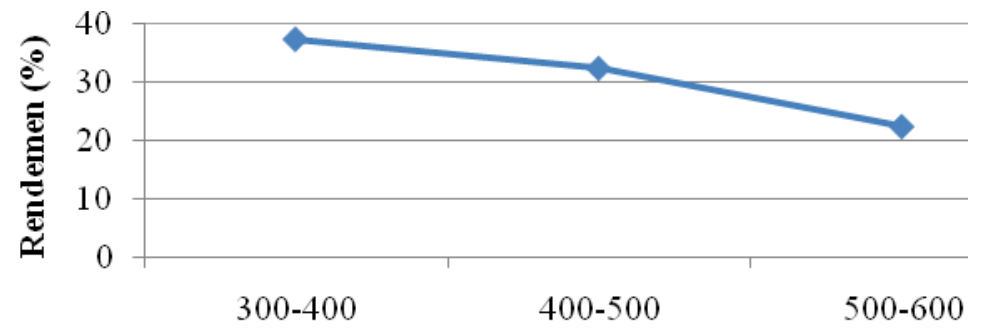

Temperatur $\left({ }^{\circ} \mathrm{C}\right)$

Gambar 5. Grafik pengaruh variasi temperatur terhadap rendemen biochar

3.5. Karakteristik Biochar Dari Ampas Aren.

Berdasarkan hasil uji kadar air, $\mathrm{pH}, \mathrm{C}-$ Organik, N, P dan

$\mathrm{K}$ untuk masing-masing range suhu di Laboratorium
Balai Pengkajian Teknologi Pertanian Yogyakarta dan CV. Chem-Mix Pratama.

Tabel 2. Karakteristik biochar ampas aren pada berbagai suhu

\begin{tabular}{cccccccc}
\hline No. & $\begin{array}{c}\text { Temperatur } \\
\left({ }^{\circ} \mathbf{C}\right)\end{array}$ & $\begin{array}{c}\text { Air } \\
\mathbf{( \% )}\end{array}$ & $\mathbf{p H}$ & $\begin{array}{c}\mathbf{C}- \\
\text { Organik } \\
(\mathbf{\%})\end{array}$ & $\begin{array}{c}\mathbf{N} \\
\mathbf{( \% )}\end{array}$ & $\begin{array}{c}\mathbf{P} \\
\mathbf{( \% )}\end{array}$ & $\begin{array}{c}\mathbf{K} \\
(\mathbf{\%})\end{array}$ \\
\hline 1. & $300-400$ & 4,45 & 5,6 & 14,63 & 0,71 & 0,10 & 0,63 \\
2. & $400-500$ & 5,26 & 5,8 & 13,49 & 0,73 & 0,13 & 0,49 \\
3. & $500-600$ & 3,22 & 6,1 & 15,66 & 0,92 & 0,09 & 0,58 \\
\hline
\end{tabular}

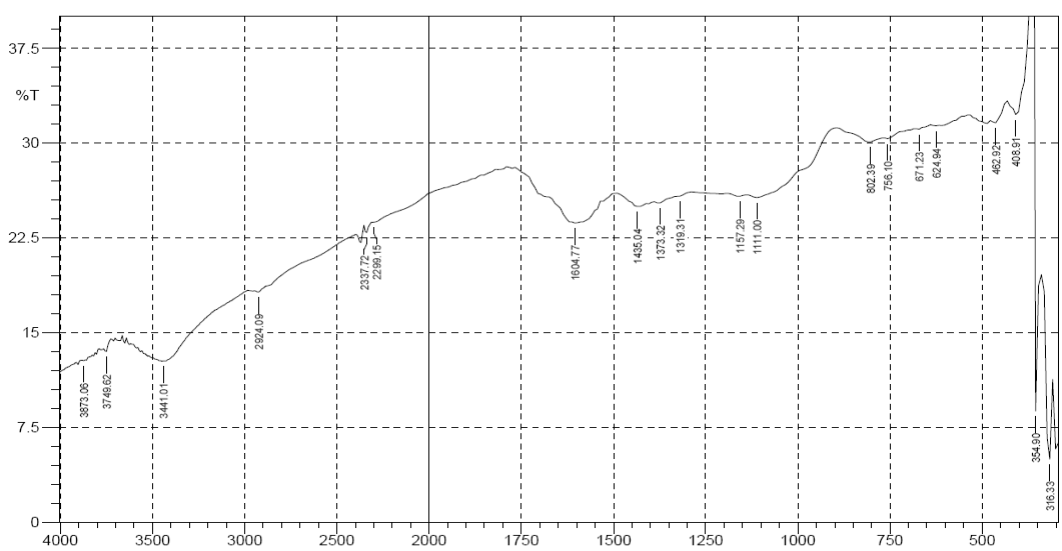

Gambar 6. Analisis FTIR biochar pada range suhu $400-500{ }^{\circ} \mathrm{C}$

Hal yang dapat diamati dari pengukuran spektrum IR pada Gambar 6. dan vibrasi tekuk pada bilangan gelombang $1604,77 \mathrm{~cm}^{-1}$ menunjukkan adanya gugus karbonil. Sedangkan pada bilangan gelombang 2924,09 $\mathrm{cm}^{-1}$ menunjukkan adanya gugus metilen, hal ini juga ditunjukkan pada pita $1604,77 \mathrm{~cm}^{-1}$ menandakan bahwa adanya gugus alkena. Pita-pita kuat dibawah $900 \mathrm{~cm}^{-1}$ menunjukkan bahwa spektrum ini dari senyawa aromatik. Adanya beberapa pita di bawah $900 \mathrm{~cm}^{-1}$ membuat sukar untuk memutuskan sifat dari substitusi benzene. Selain itu, pada bilangan gelombang antara 3400 - $2400 \mathrm{~cm}^{-1}$ menunjukkan adanya gugus asam karboksilat. Sehingga dapat disimpulkan bahwa senyawa ini mempunyai gugus fungsional $\mathrm{COO}^{-},-\mathrm{OH}$, dan $\mathrm{C}=\mathrm{C}$, yang berarti tersusun atas rantai karbon siklik (inti benzene) dengan substitusi $\mathrm{OH}$ dan $\mathrm{COO}$. 


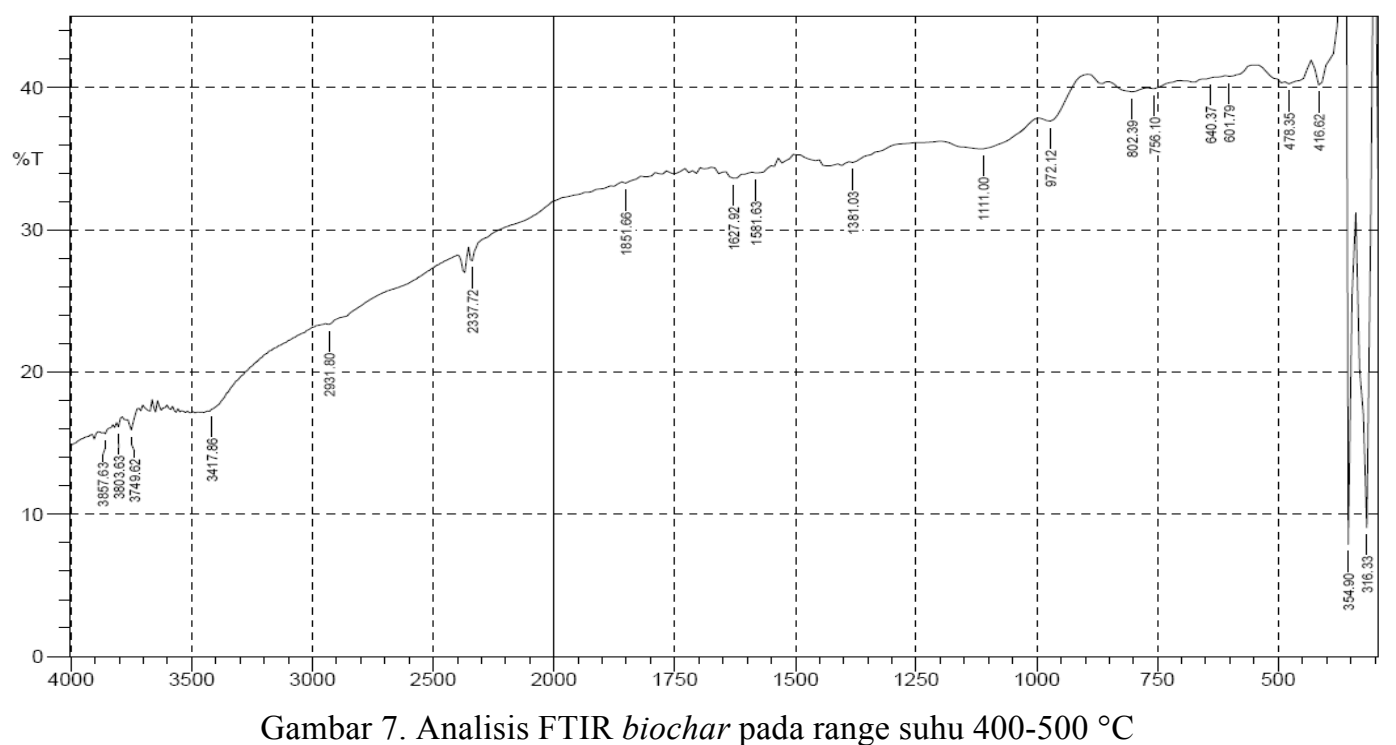

Hal yang dapat diamati dari pengukuran spektrum IR pada Gambar 4.6. dan vibrasi tekuk pada bilangan gelombang $1627,92 \mathrm{~cm}^{-1}$ menunjukkan adanya gugus karbonil. Sedangkan pada bilangan gelombang 2931,80 $\mathrm{cm}^{-1}$ menunjukkan adanya gugus metilen, hal ini juga ditunjukkan pada pita $1627,92 \mathrm{~cm}^{-1}$ menandakan bahwa adanya gugus alkena. Pita-pita kuat di bawah $900 \mathrm{~cm}^{-1}$ menunjukkan bahwa spektrum ini dari senyawa aromatik. Adanya beberapa pita dibawah $900 \mathrm{~cm}^{-1}$ membuat sukar untuk memutuskan sifat dari substitusi benzene. Selain itu, pada bilangan gelombang antara 3400 - $2400 \mathrm{~cm}^{-1}$ menunjukkan adanya gugus asam karboksilat. Sehingga dapat disimpulkan bahwa senyawa ini mempunyai gugus fungsional $\mathrm{COO}^{-},-\mathrm{OH}$, dan $\mathrm{C}=\mathrm{C}$, yang berarti tersusun atas rantai karbon siklik (inti benzene) dengan substitusi $\mathrm{OH}$ dan $\mathrm{COO}$.

\section{Kesimpulan.}

Berdasarkan hasil penelitian dapat diambil beberapa kesimpulan sebagai berikut :

1. Dari hasil penelitian di atas dengan temperatur masing-masing $300-400{ }^{\circ} \mathrm{C}, 400-500{ }^{\circ} \mathrm{C}$, dan $500-$ $600{ }^{\circ} \mathrm{C}$, disimpulkan bahwa suhu optimal untuk mendapatkan rendemen tertinggi biochar dari ampas aren dengan berat bahan baku 200 gram didapatkan pada temperatur $300-500{ }^{\circ} \mathrm{C}$ dan lama proses 210 240 menit dengan rendemen sebesar $>30 \%$.

2. Dari hasil pengujian terhadap ketiga range temperatur yang telah diteliti ditemukan, bahwa : 1) pada temperatur $300-400^{\circ} \mathrm{C}$ diperoleh kadar air sebesar 4,45\%, pH 5,6, kadar C-organik 14,63\%, kadar N 0,71\%, kadar P 0,10\%, dan kadar K 0,63\%, 2) pada temperatur $400-500^{\circ} \mathrm{C}$ diperoleh kadar air 5,62\%, pH 5,26, kadar C-organik 13,49\%, kadar $\mathrm{N}$ $0,73 \%$, kadar P $0,13 \%$, dan kadar K $0,49 \%, 3$ ) pada temperatur $500-600^{\circ} \mathrm{C}$ diperoleh kadar air $3,22 \%, \mathrm{pH}$ 6,1, kadar C-organik 15,66\%, kadar N 0,92\%, kadar P 0,09\%, dan kadar K 0,58\%. Kesimpulannya bahwa kesemua indikator rendemen dan karakteristik biochar pada ketiga range temperatur yang diteliti memenuhi persyaratan sebagai pembenah tanah yang telah ditentukan oleh International Biochar Initiative (2010). Dan juga diperoleh dari hasil uji FTIR bahwa biochar ampas aren mengandung gugus karbonil, karboksil, dan inti benzene. Pemanasan lambat

mengubah gugus karbonil dan karboksil menjadi karboksilat di dalam rantai benzene yang sangat potensial untuk menahan nutrient yang dibutuhkan tanah

\section{Daftar Pustaka.}

Babu, B.V., Chaurasia A.S., 2004, Dominant Design Variables in Pyrolysis if Biomass Particles of Different Geometries in Thermally Thick Regime, Chemical Engineering Science.

Bergman, P.C.A., 2005. Torrefaction for biomass upgrading, 14th European Biomass Conference \& Exhibition, Paris

Ferizal dkk, 2011rang hayati (Biochar) sebagai pembenah tanah.

Firdayati, M. dan Handayani, M, 2005, Studi Karakteristik Dasar Limbah Tepung Aren, Jurnal Infrastruktur dan Lingkungan Binaan, Vol. I No. 2.

Gani, Anischan., 2010, Multiguna Arang-Hayati Biochar, Sinar Tani Edisi 13-19 Oktober 2010.

Kusmiyati, Heni. 2007, Karakteristik Limbah Tepung Aren dan Permasalahan Lingkungan yang ditimbulkan di Desa Daleman Tulung Kabupaten Klaten. Teknik Lingkungan, Yogyakarta.

Leading Carbon Ltd., 2010, Product Definition and Standard DRAFT, International Biochar Initiative.

Lehmann, J., 2005, Amazonian Dark Earths, Cornell University USA.

Loppinet-Serani, A., Aymonier, C., Cansell, F., 2008, Current and Foreseeable Applications of Supercritical Water for Energy and The Environment, ChemSusChem 1, 486 - 503. 
dan Pemanfaatan Sampah/Limbah Perkotaan, Magister Sistem Teknik, UGM.

Nurida, NL., dkk, 2011, Kualitas limbah pertanian sebagai bahan baku pembenah tanah berupa biochar untuk rehabilitasi lahan, Jurnal Pertanian.

Peters, J.H., Barry, M., Fraser, N., and Collin, E.S., 1995, The Copyrolysis of Poly (Vinyl Chloride) with Cellulose Derived Materails as A Models for Municipal Solid Waste Derived Chars, Fuel.
Potter C, M. Soepardi, Alulia Gani, 1994. Limbah cair berbagai industri di Indonesia. Sumber pengendalian dan baku mutu. WMD Bappedal, Jakarta

Sastrohamidjojo, H., 2007, Spektroskopi, Liberty Yogyakarta.

Williams, T.P., Besler, S., 1992, Pyrolysis of Municipal Solid Waste, Journal of The Institute of Energy 